\title{
THRESHOLD CONCEPTS IN CHEMICAL ENGINEERING DESIGN
}

\author{
Sense Publishers
}

\section{INTRODUCTION}

This chapter explores the role of problem-based learning (PBL) in facilitating students' engagement with design components of a chemical engineering degree at the University of Strathclyde (UoS), where students are required to plan and evaluate a manufacturing process. Teaching staff previously identified issues with students' abilities to deal with open-ended problems in chemical engineering and to accept open-endedness itself, identifying open-endedness as a threshold concept in design. Work was subsequently undertaken to develop appropriate PBL content to address this threshold concept and associated drop-out rates. A longitudinal programme was engineered to support student learning via a dedicated PBL module, enhancing the students; experience. The benefits of such a programme go beyond the students' academic career and provide significant impact in achieving success in the real world. The chapter presents findings from this work and builds on the use of threshold concepts in PBL, as introduced in the works of Land and Savin-Baden, relating them to the engineering discipline and reporting on the successful incorporation of PBL activities in early years to help students overcome the liminality that results from open-ended working.

\section{LITERATURE}

Since its incorporation in 1969 at McMaster University's School of Medicine, PBL has found critically proven application in a wide variety of disciplinary contexts, including Chemical and Process Engineering (CPE) (Woods and Sheardown 2004; Schwartz, Webb, and Mennin 2001; Savin-Baden 2003; Delisle 1997). Here, we consider PBL to be a student-centred pedagogic activity that requires students to use reasoning and reflection to construct their own learning. As such, it focuses on active learning, independent enquiry, and developing proactive approaches to open-ended problems, and is well suited to examining troublesome aspects of core subjects, such as thermodynamics, process analysis, heat transfer, and fluid flow (Cline and Powers 1997; Hammond 2013; Rossiter and Biggs 2008; Woods 1996). It is also manifestly useful in teaching design where students are encouraged to develop new strategies

Fletcher, A., \& Boon, S. (2018). Threshold Concepts in Chemical Engineering Design. In M. Savin-

Baden, \& G. Tombs (Eds.), Threshold Concepts in Problem-based Learning Rotterdam, The

Netherlands: Sense publishers.

(C) 2005 Sense Publishers. All rights reserved. 
and processes, and to incorporate new knowledge in solving open-ended problems (Hasna 2008; Moore 2005).

The study and analysis of threshold concepts is less established in CPE, but has seen increasing critical attention and application over the last decade (Davey 2012; Fletcher and Boon 2013; Sibanda, Case, and von Blottnitz 2011; Streveler et al. 2008). Here, we consider threshold concepts to be transformational in students' perception of chemical engineering and, while the majority of engineering teaching has been geared towards the acquisition of foundational knowledge (Davey 2015), threshold concepts, i.e. core chemical engineering understanding, threshold concepts hold a particular power in the area of design, where open-endedness plays a larger role. Open-endedness has previously been identified as a threshold concept by Male et al., who surveyed 435 first-year engineering students registered on an integrated engineering foundation course, concluding that open-ended problems were a threshold concept as a consequence of their transformative nature and troublesome features, including 'recursive solutions' and 'identifying which variables and constraints are significant' (Male 2012).

Seeing open-endedness as a threshold concept is not new; for example, previous work in teaching Liberal Education has suggested that 'Gaining a deep understanding that most problems are solvable with sustained effort we suggest marks a fundamental and irreversible threshold in students' development of problem-solving skills' (Wismath, Orr, and MacKay 2015). Similarly, the field of Architecture requires students to engage with ill-defined problems and open-ended situations (Barnett 2000), which is said to align with the framework of threshold concepts (Land, Meyer, and Flanagan 2016). Finally, Land et al. reported on the concept of moving from designing to specifications to designing the specifications, where students engaged in design must 'make a plan for this' or 'propose a solution to that' and 'proactive knowledge is better served by engaging the learner in formulating some of the specifications or interpreting rather open-ended specifications' (Barnett 2000). This last work is particularly important in defining the role of the engineer within this open-ended context i.e. one who creatively designs a process, including definition of process boundaries.

As stated by McCartney et al., liminality is 'the transitional period between beginning to learn a concept and fully mastering it' (McCartney et al. 2009), such as the transition of student engineer to professional engineer. During a student's project to design a chemical engineering plant, it is this move towards professional working, where an end product or process is often unknown, requiring creative construction of new systems, which causes students most concern. Prior to design, students have predominantly attempted closed questions, i.e. problems that have a singular answer, requiring them to learn and apply fundamental principles, laws, standards, and other immutable elements to specific set tasks; even those problems that may be considered to be a move to open-endedness are structured and do not provide students with the reflective component required to work through the liminality of such a new mode of working. Design, therefore, requires students to 'breakaway' from their established learning constructs, requiring a completely different way of 
working, and the open-endedness of this mode of learning is, therefore, a threshold concept for CPE students.

Introducing students to open-ended scenarios earlier in their studies, via PBL methods, primes them for new, and often disquieting, thresholds and the liminal spaces between and should provide a progressive route to overcoming the threshold concept or open-endedness. PBL provides enhanced learning experiences where students encounter meaningful and challenging problems that bring about a reexamination of pre-existing knowledge and results in the generation of new hypotheses, processes, and understanding. The step or phase between pre-existing knowledge and new knowledge, between former and current understanding, is a liminal space that challenges students to make sense of the discordant incongruity, to re-evaluate, re-discover, and ultimately re-define the phenomenon or experience encountered. Such change does not come without cost, however, and many students struggle with threshold concepts and their concomitant liminality. From a CPE perspective, the open-endedness of the Year 4 (Y4) design, which requires students to work in a PBL setting, has proven to be a troublesome threshold. Below, this chapter looks in-depth at how staff in CPE articulated open-endedness as a threshold concept in the PBL design component and what means were put in place to support students to navigate liminality, negotiate new understandings, and benefit more meaningfully from the open-ended design experiences.

\section{PROBLEM-BASED LEARNING IN CHEMICAL AND PROCESS ENGINEERING (CPE) AT THE UNIVERSITY OF STRATHCLYDE}

Design is undertaken by all students in Y4 of the Chemical Engineering degree at UoS, comprising approximately 80 students across all three degree cohorts within CPE, i.e. BEng/MEng Chemical Engineering and MSci Applied Chemistry and Chemical Engineering, and comprises 60 credits in the second semester of Y4. Current delivery of the module is the completion of one process design divided into three phases: scoping, detailed design, and evaluation and reflection. The whole cohort is distributed into teams of six students with each team assigned an academic supervisor. The group size allows assignment of a manageable number of groups per supervisor, while still permitting individual student engagement. Group composition covers a range of previous academic abilities with no positive bias for gender, ethnic origin or age. Overall, the project provides an opportunity to experience common intellectual experiences, work in learning communities on a collaborative project, hence, an experience of 'Engineering as Engineering is done' (Kuh 2008; Association of American Colleges 2007). Students meet their supervisors weekly, and are responsible for managing their own schedule and workload in the remaining time. Team members must work together to create a coherent report from their individual contributions, hence, critical evaluation of the importance of information is crucial as each section must add value to the final report. The project provides an opportunity for students to gain experience of, and credit for demonstrating, leadership, collaborative working, critical analysis, creativity, and synthesis and 
integration of information. Supervisor meetings are not formally assessed, as is the case in some other Universities, however, CPE recognises that these provide students with opportunities to give oral feedback to their colleagues and supervisor, while the compilation of the final document requires critique and feedback on the work of other team members.

The open-endedness experienced in design is also a threshold concept, wherein students experience a transformative shift in mind-set towards the design question posed, iteratively evaluating and reconstructing their approach over time. Therefore we consider design a liminal process, whereby students must negotiate a troublesome pathway from previous perceptions of design and structured modes of design working to new modes of open-ended working, adopting a new understanding of the complexities of designing a novel process.

Previous offerings of the module highlighted issues that students were experiencing with the threshold concept of open-endedness, notably a significant drop-out rate and anecdotal confusion and stress throughout the cohort, as students grappled with the concept that there is not a pre-defined 'right answer' and that they are required to make assumptions or rationalise comparable data as and when required. In order to remedy the situation, academic staff incorporated a dedicated PBL module in the first semester of Y4. The intention of this new focus was to guide students through the liminal state often experienced in design projects, by working on discrete problems in preparation for tackling more complex tasks. Questions required students to draw on prior knowledge, apply concepts in new scenarios and made educated assumptions about missing data. While this enabled students to deal with the semester two design project more confidently and competently, it also highlighted the need for earlier embedding of PBL to support these later-year activities, as the liminality experienced in design was now shifted to the Y4 PBL module.

Teaching, across all years, focuses heavily on teamwork, thereby simulating reallife expectations of practising chemical engineers; these activities are designed so as to promote participant engagement for improved performance, including collaborative working and shared intellectual experiences. Previous research has identified several transferable skills, including communication, teamwork, problemsolving, numeracy, IT literacy and self-management, as key to enhancing employability; which aligns with the Institution of Chemical Engineers' learning outcome that graduates must possess skills such as communication, time management, team working, inter-personal, effective use of IT including information retrieval [considered] valuable in a wide range of situations. Certain skills within this list, including management, are considered under-taught in Universities, suggesting that teaching instances to enhance such skills development would be welcomed by both employers and prospective employees. Reviews of management practices within UK industry also suggest that graduate recruitment and progression is linked to the development and demonstration of group working skills. Hence, within CPE, students work in teams throughout all years, thereby experiencing many different groupings, thus, working practices. 
As an engineering sub-discipline, chemical engineering focuses on designing, constructing, implementing, operating and managing process plants and systems. The curriculum consequently comprises a range of knowledge and skills preparing students to undertake the aforementioned tasks, with modules on fundamentals and core concepts in earlier years, and more specialist modules in later years. This breadth of the subject area requires diverse teaching and assessment methods to support students' development via increased engagement and enhanced performance. At UoS, this knowledge and skills development underpins the capstone design project within Y4 of chemical engineering, as described above, required for course accreditation and allowing students to subsequently apply for chartered status.

\section{IDENTIFYING THRESHOLD CONCEPTS IN CHEMICAL AND PROCESS ENGINEERING PROBLEM-BASED LEARNING}

As outlined above, open-endedness is the core threshold concept in design, requiring students to act independently, trusting their own judgement in decision and assumption making, as well as accepting that there is no definitive answer for the problem set. After identifying the issues experienced in design and including a PBL module in first semester of Y4, discussion between staff involved in Y4 teaching identified that this action had only served to shift the issue to an earlier point in the same year, hence, the decision was taken to incorporate PBL in Y2-3 to support students in their journey towards design. Introduction of these components was evaluated for students undertaking PBL in Y2, using ethnographic observation and direct surveying of 86 students' opinions to assess the impact of this change. The former involved an MEng project student observing tutorials and synopsis lecture sessions to record student interactions with tutors and the class environment, while surveys, combining both Likert scale questions and free text answers, conducted ta the mid and final points of the class provided feedback on students' perceptions of the new method of working.

A stated above, observations by staff teaching on the previous version of design, often within supervisor meetings, indicated that students frequently found the openendedness of the design project to be problematic:

'They struggle to define the initial problem and also to accept that there are a range of answers that could work'.

'Even the good ones (students) find it difficult to make assumptions and work towards an unknown outcome, it's hard then to explain that they need to be critical and evaluative rather than having a concrete 'right' answer.'

Staff would face constant requests for affirmation, even from extremely able students, and the designs submitted would often be similar as students found it difficult to have confidence in alternative ideas; some students struggled with design for several weeks before withdrawing completely from their studies, admitting that 
they found it to be completely overwhelming. Whereas classes experienced in earlier years (Y1-3) had always required determination of set quantities, such that there was a definitive 'right' answer, the nature of design means that several solutions may be viable and there is not a single outcome expected. One student's reflection on design was:

'It's so different to everything we've done before. Sometimes I found it hard to get started as there seemed so much to do and I didn't want to get it wrong.'

The students, therefore, were struggling with the liminalities associated with selfassessment and criticality, which are essential for personal and professional development. In addition to these threshold concepts (Meyer and Land 2006), wherein students engage with and apply knowledge gained in core classes to assigned tasks, often revisiting, and maybe rationalising, troublesome knowledge as part of the process, further research, surveying 72 staff and student respondents, by a combination of Likert scale set questions and free-text boxes, into their perceptions of design identified several issues related to delivery of chemical engineering design at that time. The realisation there was no single 'right' answer came as a shock to students, who struggled to accept that their supervisors themselves might not know an absolute process for success or definite target to which the students should be working. Student's commented that:

'You expect your supervisor to know what is needed but the feedback is often vague. I want to know for sure if I'm on the right track so we often compare working between groups as at least one of us are designing the same unit.'

'It was a nice change to be creative but this did mean we were several weeks in with no clear plan of what to focus on. Our supervisor helped us see a path forward but it was sometimes still unclear till just before hand in.'

Which demonstrates not only the students need for validation, but that they seek resolution by other means when they feel their supervisors are unable to categorically approve their working. This tension of guidance and affirmation is also felt by staff:

'It's evident that we are there to help the students by guiding their work but they also want us to tell them whether something is right or wrong, and to give them definite yes or no answers to their questions. Sometimes they ask the same thing in several ways just to try and get you to do that. I reflect the question back to them and ask them to discuss their options as a group but that often highlights the fact that they haven't been doing that in the time between meetings.'

This last comment highlights further frustration that was born from high expectations both by staff and some students and the fact that many students found themselves insufficiently skilled to deliver. Coupled with a lack of group identity, understanding of team roles, project ownership, and resulting group cohesion: there 
was a tendency for students with poor exam performance in semester one to disengage from the design project once their exam results were released, which ultimately impacted the whole team. Hence, the introduction of PBL as a supportive pedagogic activity and this chapter presents evaluation of students' earlier experiences of this method of learning.

\section{MANAGING THRESHOLD CONCEPTS IN CHEMICAL AND PROCESS ENGINEERING PROBLEM-BASED LEARNING}

Analysis of the previous delivery of design resulted in recommendations to enhance transferable skills development within the module, by establishing critical analysis and problem-solving abilities though alignment of embedded PBL activities. The introduction of such methods across all years of the degree program, with structured, increasing complexity, had been successful in other chemical engineering programmes. The programme at UoS aimed to increase students' skill sets, increase students' understanding of team roles and, therefore, their personal identity, so increasing student engagement on the project, thus, improving ownership of work, promoting reflection on past performance and experiences, and supporting students in their acceptance of the idea of open-ended problems, thereby reducing the stress experienced in design.

The first step taken was to introduce a problem-solving module, featuring openended problems that students were required to tackle in teams, to semester one of $\mathrm{Y} 4$, thereby providing some direct support for development of critical evaluation and reasoning. While successful in introducing students to the concept of open-ended problems, the module had significant failings. Firstly, the students taking the class had experienced four years of traditional, lecture-based teaching prior to and concurrently with the problem-solving module; consequently, the PBL delivery was a new concept and there was no transition period for the students to adjust to the requirements of this new mode of teaching and, therefore, learning. As a consequence of past experience, hence, prior familiarisation, this group of students were less likely to embrace PBL at that time. Secondly, students had not identified their role within the process: PBL contrasts starkly with traditional teaching modes, by requiring students to identify and state problems, before classifying information and learning goals, in order to produce a working plan; hence, the lack of structure in the former requires greater communication between teacher and student. A third issue was the students' perception of the class, in that it focussed on problem-solving and not PBL, primarily due to the lack of prior exposure but also as a result of the significant increase in difficulty of the problems posed compared to traditional tutorial questions from previous classes. Consequently, the students' initial experience was one of confusion and reduced engagement, indicating that Y4 was too late for this first instance of PBL. 
ASHLEIGH FLETCHER AND STUART BOON

\section{Students perceptions of design}

During the time of this initial introduction of PBL in Y4, students' perceptions of design were investigated as outlined above, by surveying students' views of the module, in order to determine the skills they expected to develop during the project and those that they thought were developed post module, including those relating to PBL.

Pre-design When asked about the skills that they expected to develop within design, students listed many of those outlined in the module learning outcomes and aligned with the skills identified earlier, such as teamwork, problem-solving, time management, self-management, innovation, leadership, project management and critical thinking. While some students recognized these as being particularly attractive for their future prospects:

'During this project I expect to develop and improve my group working skills and my ability to work as part of a team. Interpersonal and group working skills are core skills, essential in the modern day work place. The opportunity to improve these skills is advantageous in preparation for employment after university and this design project is the ideal opportunity to improve and exhibit the development of these skills to employers.'

Others expressed genuine concern for the process that they were about to undertake, which often related to the problem-solving aspects:

'I'm concerned with the design aspects we haven't been taught. I'm also concerned about what group I might be put in and that it won't have someone really good at problem solving because this is a skill I personally need to improve on so someone to help would be ideal for me.'

'Concern about not matching the pace of other group members who are able to create a specific goal to aim towards.'

It is interesting that students identify problem-solving as necessary and a skill to develop during design, while others are struggling with the idea of identifying a final objective on which to map their work plan. While problem-solving was highlighted, possibly as a result of having the embedded PBL module, none of the students identified working on unknown systems or emulating a professional workplace or project.

Post-design The same students were asked to identify how design had helped to develop their skills sets, and several mentioned increased criticality and decisionmaking, often without explicitly identifying it as such, and to do so within the required timescale:

'In previous coursework, I have always had a need to look over things excessively to ensure fine tuning. Whilst this has still been done to an acceptable standard in my design project, I have also developed the ability to 
decide when the work is of good quality and move on when the time is right. Such is the demand of the projects.'

'My decision making skills, I believe, have been enhanced significantly.'

'Design has taught me to focus in on what is important and will add value to a project and what is extraneous detail that would be nice to include but is not essential. It has helped me learn when to move on from an idea and not spend too long on one particular task.'

This latter comment alludes to the, often observed, increase in confidence in their own assessment of a process, which students exhibit towards completion of the design project. This seems to provide students with an appreciation of applying their engineering knowledge to a real problem:

'I feel that I have significantly improved as a chemical engineer. This semipractical work has really increased my knowledge and understanding of many key areas of the course, most of which I would not have learned simply from lectures.'

'I felt I learned more chemical engineering skills doing the design project than I have through any classes. The whole project means you self tech (sic) yourself all the necessary skills, with the aid of chem eng (sic) books.'

'Whilst the design project has ultimately been one of the most challenging tasks of my life, it has also been the most rewarding and I feel it sets me up very well for life in a professional chemical engineering environment.'

While criticality was valued, there seemed to be little reflection on the PBL aspects of design and it may well be that the prior exposure to open-ended learning offset their acceptance of such working. It is notable that this cohort saw a significant improvement in student retention rates compared with previous years.

\section{Supporting design}

These perceptions of design, and the concerns raised by the Y4 PBL class, indicated that a similar class structure in earlier years could help support students' development and provide a structured introduction to open-endedness and PBL in advance of their project year. Y4 design builds upon a more structured 20 credit class in Y3, Plant and Process Design, where students develop their design skills with significant tutoring and support; hence, the class is much less involved and less independent than Y4 design, but has been revised in recent years to provide further skills development. Again, students often experience theoretical difficulties with Y3 design, partly attributable to lack of engagement with key concepts in core classes but also related to the previously identified open-endedness and lack of a definitive right answer. Consequently, while Y3 design is now used to assess skills development within this year of teaching, it does not offer a suitable platform for 
exposure to open-endedness and the support of PBL prior to design in Y4. Subsequently, Y2 was identified as the most appropriate for introduction to PBL. To this end, the 20-credit Mathematics module has been split to contain 10 credits of Mathematics and 10 credits of problem-solving, while the 20 credit Chemical Principles and Thermodynamics module has been overhauled to use PBL principles throughout. This latter class offers a combination of highly numerical working and conceptual development, very much akin to design, making it an ideal candidate for learning style development.

\section{Hybrid problem based learning in Thermodynamics and Chemical Principles}

While embracing the tenets of PBL, to promote active learning and encourage peer teaching, the class is not entirely PBL based but rather uses a hybrid problem based learning (HPBL) approach. Such methods have been shown to be statistically insignificant with respect to students' acquisition of factual knowledge, compared to traditional teaching methods (Carrió et al. 2011); however, it does offer increased learning satisfaction (Chilkoti et al. 2016) and improved critical thinking (Lian and He 2013). Students receive formal teaching and guidance into the areas highlighting concepts that must be understood to tackle problems presented in associated workshop sessions; many of these concepts are open-ended. However, for most elements, closed questions are designed to allow students to develop confidence in their knowledge and abilities prior to attempting the open-ended problems. In this module, students are expected to read notes and watch extended video lectures in advance of synopsis lectures, which highlight key concepts required for associated tutorials. Adopting a HPBL approach, as a precursor to Y4, allows students to develop critical thinking skills, mitigating the possible risks of a lack of previous PBL experience and issues relating to group dynamics, while also providing the benefits of teamwork, communication, self-motivation and closing the feedback loop (Chen et al., 2006). It still places students firmly at the centre of the learning process, with an increasing level of control of their own learning, and opportunities to experience and articulate their learning within their groups.

\section{Class redesign}

The module was redesigned in 2015 and there have been two successive evaluations of the changes made, with feedback into the on-going development of the module. Student opinions were sought by survey and in the second year of offering, students were observed in class by an independent researcher to provide an overview of the level of engagement with the different aspects of learning. 
Class format In the 2015/16 delivery, students received two hours of lectures and one of tutorial per subject in the module, which was adverse to creating a PBL environment, hence, in 2016/17 there was a move to online pre-lectures and one hour of synopsis, thereby addressing the issue of two hours tutorial time and the 2015/16 comment:

'Lecture seemingly unrelated to tutorial problems.'

There were four tutors per class section, comprising the academic staff member and three postgraduate tutors, selected on a competitive basis for their prior knowledge and previous experience.

Tutors In the first evaluation, it was highlighted that tutors should adopt the role of mentors in future years and, related to this is, the need to establish a good working rapport with assigned teams, with tutors assisting only a subset of the cohort. This allows students to engage with their tutors by developing a positive interaction, while also allowing tutors to keep track of students' performance within the tutorial. 2016/17 students' views were generally very positive towards the tutors:

'They were helpful.'

'They made sure that every group was attended to and had their questions answered.'

'Helped when asked.'

Group composition In 2015/16, students were randomly assigned to teams and both lecturers noted significant absences from class, despite over $60 \%$ of respondents stating that they valued the tutorial sessions, , particularly for minority students (by gender, ethnicity etc.), with one 2015/16 student reporting:

'Few presences (almost alone) in my tutorial group.'

Hence, the decision was made to allow students to choose their own group compositions in future years, thereby increasing ownership of the process and their learning. Significant improvements in engagement were observed with over $85 \%$ regular attendance at tutorials. 
Worked solutions Each week two groups of students are selected to submit their materials as worked solutions for the rest of the group. These workings are annotated with comments from the lecturer and posted on the virtual learning environment for the benefit of all students. Previously, students were advised early in the session of who would be submitting their workings, however, this often resulted in the group dividing the work and tackling the questions independently, therefore, negating the team-working aspect of the session. In the 2016/17 session the students were advised of allocation towards the end of the session to avoid a similar situation, but at such a time as to allow them to ask for any further guidance before the end of the tutorial, thereby addressing the 2015/16 comment:

'Group work not satisfying (made me lazy).'

Question layout and composition Finally, it was recognized in previous years that the layout of the tutorial sheet was integral to students' engagement, most notably that if the initial questions were particularly difficult, students' confidence was low and they often attempted very little of the tutorial. While reorganisation maintained the types of questions that resulted in good self-reflection from the 2016/17 cohort:

'It allows us to apply our knowledge to real-life problems.'

In 2015/16 more than one student noted that:

'Tutorial questions often too difficult.'

While another suggested:

'Provide some simple questions to build basic knowledge.'

Thus, the question sheets were restructured for 2016/17, adding some additional, open-ended, questions to provide a structured exercise, which was seen to increase student engagement and confidence as students were able to believe in their growing abilities (Jackson, 2011).

Iterative restructuring While the 2016/17 cohort has benefitted from these changes, there is always room for improvement, hence, class timetables will be altered next year as students highlighted problems with timings of tutorials and lectures due to reliance on the required self-study centred teaching style or PBL:

'More time between lectures and tutorials [they are on the] same day so no time to consolidate.'

'Sometimes the lectures move way too fast in the class, which makes it hard to understand and work effectively in tutorials.'

Some mitigation of this issue would have been possible had the students undertaken the self-study portion of the class more rigorously, however, it also 
highlights the need for reiteration of the newly encountered learning style arrangements and does identify the students' real need for consolidation time:

'Having lectures and tutorials right next to each other doesn't give time to read over [the] lecture and consolidate knowledge before [the] tutorial.'

'Not enough time between lectures and tutorials to fully absorb material for questions.'

This cohort also highlighted the positive impact that PBL can bring with increased satisfaction with the course, suggesting that students may well benefit from the use of similar teaching methods in other classes:

'Best format of any class I've had.'

'Feels more thought out and structured.'

and, despite contact times being similar for other modules:

'Get more help in tutorials - tutors encourage me to understand problems.'

This last comment touches upon the basis for PBL working and highlights that some students are benefitting from the changes. As stated above, tutorial attendance has increased, while observation from the classroom showed students were more engaged with their groups, were participating in active discussion and gave careful consideration to the questions posed to their tutors.

\section{DISCUSSION}

As a means of supporting students' engagement with open-endedness in the design element in Y4 of the CPE degree, the introduction of PBL into to earlier years has necessitated careful consideration and planning of suitable activities. The use of HPBL in Y2 has allowed staff to introduce Y2 students to open-endedness and PBL within a structured learning environment. The benefits of such working have been many: students have supported experiences of open-ended working earlier in their degree; tutors feel valued and not simply as gatekeepers of answers; staff have observed higher levels of engagement and a deeper level of understanding and criticality, as evinced from the quality of questions posed in class; and, finally, students engaging with HPBL performed better. The issue of open-ended working is crucial in chemical engineering and chartership requires that design must be completed by all students. Consequently, students invariably experience openendedness and the liminality that coincides with it. In order to be successful in CPE, they must each address this threshold concept and develop the skills necessary to work in complex and challenging systems and environments. Chemical engineering students, therefore, have a need to engage positively with educational strategies aligned constructivism; in design, students are not only expected to tackle openended problems but also to actively construct and develop new concepts or ideas that build upon previously acquired knowledge or experiential learning, whilst 
undergoing social constructivism during mentoring by an academic supervisor who acts more as a facilitator of learning and group engagement. Consequently, introducing students to the nature of open-ended working in earlier years, allows them to accept such modes of working and deal with this threshold concept, such that when they do experience design, the negative impact of PBL is negated and students can embrace the educational constructs discussed above, which should additionally improve their engagement with troublesome knowledge by reducing the demands of the experiential activity.

\section{CONCLUSION}

There is evidence of improved student engagement and attainment in core classes by working in a PBL mode; by introducing more structured, PBL modules in year two and enhancing the open-ended aspects of design throughout year three, students can become more skilled in working on open-ended problems and dealing with the open-endedness of design. Positive outcomes resulting from the inclusion of problem-based elements include: increased engagement, mitigated stress, bolstered confidence reduced confusion, and improved student retention, while graduates of the programme also reported improved performance in recruitment processes and within the workplace.

There is a clear benefit of introducing PBL to chemical engineering students to support their core classes, as the research presented here indicates that the students undertaking such structured learning will be better equipped for their capstone projects. Such improvements go beyond the classroom and provide advanced skill sets and working practices that will enhance employability. Using PBL in early year classes, to underpin advanced project working in later years, is worthy of consideration for chemical engineering teaching as well as the wider engineering discipline.

\section{REFERENCES}

Association of American Colleges, Universities, and National Leadership Council,. 2007. College learning for the new global century: A report from the national leadership council for liberal education \& America's promise: Assn of Amer Colleges.

Barnett, Ronald. 2000. "University knowledge in an age of supercomplexity." Review of. Higher education 40 (4):409-22.

Carrió, M, P Larramona, JE Baños, and J Pérez. 2011. "The effectiveness of the hybrid problem-based learning approach in the teaching of biology: a comparison with lecture-based learning." Review of. Journal of Biological Education 45 (4):229-35.

Chilkoti, Geetanjali, Medha Mohta, Rachna Wadhwa, Ashok Kumar Saxena, Chhavi Sarabpreet Sharma, and Neelima Shankar. 2016. "Students' satisfaction to hybrid problem-based learning format for basic life support/advanced cardiac life support teaching." Review of. Indian journal of anaesthesia 60 (11):821.

Cline, Matthew, and GJ Powers. 1997. Problem based learning via open ended projects in Carnegie Mellon University's Chemical Engineering undergraduate laboratory. Paper presented at the Frontiers in Education Conference, 1997. 27th Annual Conference. Teaching and Learning in an Era of Change. Proceedings. 
THRESHOLD CONCEPTS IN CHEMICAL ENGINEERING DESIGN

Davey, KR. 2012. "Results from a study with Threshold Concepts in two chemical engineering undergraduate courses." Review of. Education for Chemical Engineers 7 (3):e139-e52.

2015. "A detailed anatomy of students' perception of engagement and their learning a threshold concept in core chemical engineering." Review of. Education for Chemical Engineers 11:e1e20.

Delisle, Robert. 1997. How to use problem-based learning in the classroom: Ascd.

Fletcher, Ashleigh, and Stuart Boon. 2013. "Proposed vertical integration of prior learning to support students undertaking Chemical Engineering Design." Review of. Education for Chemical Engineers 8 (2):e72-e85.

Hammond, Michael. 2013. "Problem-Based Learning in the Engineering Curriculum-Is it suitable for first year undergraduates?" Review of. Inspiring Academic Practice 1 (1).

Hasna, Abdallah M. 2008. Problem based learning in engineering design. Paper presented at the Proceedings of SEFI 36TH Annual Conference, European Society for Engineering Education.

Kuh, G. D. 2008. "High-Impact Educational Practices: What They Are, Who Has Access to Them, and Why They Matter." In. Washington, US.

Land, Ray, Jan HF Meyer, and Michael T Flanagan. 2016. Threshold Concepts in Practice: Springer.

Lian, Jiqin, and Fengtian He. 2013. "Improved performance of students instructed in a hybrid PBL format." Review of. Biochemistry and Molecular Biology Education 41 (1):5-10.

Male, Sally. 2012. "Engineering thresholds: An approach to curriculum renewal." Review of. Retrieved March 31:2014.

McCartney, Robert, Jonas Boustedt, Anna Eckerdal, Jan Erik Moström, Kate Sanders, Lynda Thomas, and Carol Zander. 2009. "Liminal spaces and learning computing." Review of. European Journal of Engineering Education 34 (4):383-91.

Meyer, J. H. F., and R. Land. 2006. "Threshold concepts and troublesome knowledge: an introduction." In Overcoming Barriers to Student Understanding: Threshold concepts and troublesome knowledge, edited by J. H. F. Meyer and R. Land. Oxford: Routledge.

Moore, David S. 2005. "Preparing graduate students to teach statistics: Introduction." Review of. The American Statistician 59 (1):1-3.

Rossiter, Diane, and Catherine A Biggs. 2008. "The trials and tribulations of implementing a problem based learning approach in the freshman year of undergraduate chemical Engineering." Review of. AIChE-CEE Proceadings.

Savin-Baden, Maggi. 2003. Facilitating problem-based learning: McGraw-Hill Education (UK).

Schwartz, Peter, Graham Webb, and Stewart Mennin. 2001. Problem-based learning: Case studies, experience and practice: Psychology Press.

Sibanda, Lesley, Jenni Case, and Harro von Blottnitz. 2011. Sustainable development as a threshold concept in engineering education. Paper presented at the Conference of the South African Society for Engineering Education.

Streveler, R., R.L. Miller, D. Evangelou, and B.M. Olds. 2008. Investigating levels of conceptual understanding: A case study from thermal and transport science. Paper presented at the Engineering Conferences International.

Wismath, Shelly, Doug Orr, and Bruce MacKay. 2015. "Threshold concepts in the development of problem-solving skills." Review of. Teaching and Learning Inquiry: The ISSOTL Journal 3 (1):63-73.

Woods, Donald R. 1996. "Problem-based learning for large classes in chemical engineering." Review of. New Directions for Teaching and Learning 1996 (68):91-9.

Woods, Donald R, and Heather D Sheardown. 2004. An approach to developing students' skill in self assessment. Paper presented at the Proceedings of the 2004 American Society for Engineering Education Annual Conference \& Exposition

Ashleigh Fletcher

Department of Chemical and Process Engineering

University of Strathclyde 
ASHLEIGH FLETCHER AND STUART BOON

Stuart Boon

Organisational and Staff Development Unit

University of Strathclyde 